\title{
Study on New Media Platform Operation Model Based on Bilateral Market Economy
}

\author{
Shifan Wang ${ }^{1}$ \\ ${ }^{1}$ University of Malaya, Kuala Lumpur 50603, Malaysia,
}

\begin{abstract}
In the process of development, new media presents a completely different development mode from traditional media, namely, platform development mode. Under the effect of network effect, the new media platform can quickly gather a large number of users, and integrate the resources of all the endpoints on the platform through the platform operation, so that the information production becomes efficient and the phenomenon of collaborative production appears. The value of media platform development is mainly reflected in the construction of its bilateral economic model, and the key to the construction of the bilateral model lies in the transformation from the scale economy of the demand side to the scope economy of the supply side. This paper explores a service-oriented new media operation platform under the bilateral market economy mode, to construct a price structure for bilateral users, from the perspective of free mechanism, attention economy and supply side economies of scope. This new media operation platform can break the barriers of single information flow, build unlimited value-added services, promote the integration of information flow, capital flow and logistics platform, and thus create a service-oriented new media platform.
\end{abstract}

\section{Introduction}

In the media industry, the media faces two markets, namely, the consumer market and the advertiser market, which are interconnected and differentiated. It is generally believed that the price model of media companies is to set prices to users on both sides at the same time and obtain profits from users on both sides.

With the advent of the Internet era, people's infinite information demand space has been stimulated and released, and the platform-based development of the media economy conforms to the needs of the times. Whether it is a traditional media company or a network media company, as the main body of the media economy, they will face development issues from the perspective of platform economy. Traditional media cannot adapt to the unlimited extensibility of the platform due to the characteristics of negative cross-network externalities. It is destined to give up its dominant position in the development of media economy to that of online media. New media uses the positive feedback mechanism to rapidly expand the user base of the basic platform, which greatly impacts the audience base on which traditional media depends. Therefore, under the bilateral market economy mode, this paper explores a service-oriented new media operation platform, to construct a price structure for bilateral users, from the perspective of free mechanism, attention economy and supply side economies of scope.

\section{Structure and Characteristics of Media Bilateral Market}

\subsection{Structure}

From the perspective of the industrial characteristics of the media industry, the media connects all types of subjects, namely content product providers, advertisers and consumers. What the media sells to consumers is the content products and advertisements of the media. The content products are provided by the media or content product providers, and the advertisements are provided by the advertisers. The media sells advertising space to advertisers and the audience acquired by the media, and then advertisers use the media platform to promote their products. Therefore, from the perspective of microstructure characteristics, media is a typical platformbased enterprise with a bilateral market structure, as shown in Figure 1. 


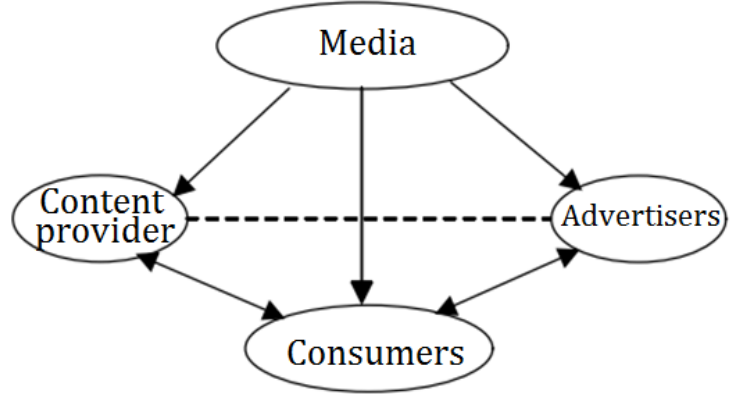

Fig1. Media bilateral market structure

According to the microstructure of the media, it can be seen that three kinds of interaction or transaction activities formed by different subjects of the media.

a) Interaction between content providers and consumers. This is an interactive activity formed by content product providers and consumers. The higher the quality of the content products provided by the content product providers in the media and the richer the content, the more consumers will be willing to consume on the media, the greater the value of the content provider. At this time, content product providers are more willing to provide content products to the media. Therefore, content product providers and consumers form a bilateral market for content products.

b) Interaction between advertisers and consumers. Consumers have a preference for the amount of media advertising, which may be advertising preference or advertising aversion, so the amount of advertising will have a certain effect on the utility level of consumers. Such effect will affect consumers' participation in the platform. Similarly, the larger the number of consumers on the media, the more motivated advertisers will be to advertise on the platform. Therefore, there is a cross network effect between advertisers and consumers, which also constitutes a bilateral market.

c) Interaction between content providers and advertisers. If the content products in the media are richer and the quality level is higher, more consumers will be attracted, which will lead to more advertisers to put advertisements on the platform. While the amount of media advertising will have a certain impact on the quality and diversity of media content products. Content providers and advertisers form a bilateral market of content and advertising.

\subsection{Characteristics}

Different from the bilateral market structure of other platform industries, the main characteristics of the media bilateral market are reflected as follow:

a) Multilateral interactivity. The bilateral market structure of other platform industries such as electronic intermediaries and operating systems only involves the participants of users on both sides, and the users on both sides are indeed the counterparties needed by the other party. However, the media platform reflects the structure of the multilateral market, including three different types of participants, and they are interactive with each other.
Consumers' demand for media is mainly reflected in media's content products, and consumers' demand for advertising depends on their preferences for advertising. The main profit model of the platform is to rely on the advertising fees of advertisers to operate. If there are too many advertisements, the consumers who are averse to advertisements will not come to the media. Therefore, an important decision issue for the media is how to adjust the relationship between advertising volume and media content.

b) Cross network externality diversity. In bilateral markets, there are cross-network externalities between users on both sides of the platform, and such crossnetwork externalities are generally developing in a positive direction. In the media, because consumers have very different preferences for advertising, we can distinguish consumers' preferences for advertising into: advertising aversion type and advertising indifferent type. For consumers with different types of advertising preferences, the amount of advertising will affect consumers' willingness to buy media. For consumers who are averse to advertising, the greater the amount of advertising, the greater the negative effect they will bring to consumers, and the less they have the incentive to buy the media; while for consumers with no difference in advertising, the amount of the media advertising volume will not have any impact on the utility of consumers. Therefore, the cross-network externality effects in the media bilateral market show diversity. It may be a positive cross-network externality effect, or it may not produce this effect, depending on the form of consumer preference for advertising.

\section{The Development Dilemma of Traditional Media}

Entering the Internet era, media integration, industry integration, and the rise of online media as a new market force have caused bottlenecks in the development of traditional media. It can be said that the platform-based development of the media economy has plunged the traditional media economy into a certain dilemma. This dilemma is the development limitation of the traditional media economy itself as a type of platform economy, which bursts into shape when encountering strong market competition from online media. Then, based on the limited perspective of platform development, we examine the plight of traditional media economic development.

\subsection{Traditional Media Lack the Advantage of Platform Expansion}

The necessary condition for market equilibrium in general market economy is negative feedback mechanism. The bilateral market of the traditional media economy also presents such a negative feedback mechanism, due to the characteristics of negative cross-network externalities. According to the multi-attribution behaviour of advertisers in the traditional media economy bilateral market, the single-attribution behaviour of the audience, and sloping pricing, the relationship between the 
advertising market and the price is positively correlated, while the relationship between media product market and price is negatively correlated. In other words, the media's pricing of the advertising market increases, and the advertising market platform effect increases, while the platform effect of the media product market decreases, and the audience decreases; the media's pricing of the advertising market decreases, the advertising market's platform effect decreases, while the media product market's platform effect increases and the audience has increases. This process is repeated until the market equilibrium is reached. The core point of the feedback mechanism is that the increase of one effect will inevitably lead to the decrease of the other effect, and any change will be offset by the reverse change it produces. Because the price demand elasticity of the media product market on the other side of the traditional media bilateral market is very small, and there is no endogenous relationship with the advertising market, the price system of the media product market itself is not in the negative feedback mechanism of the traditional media economy. This proves that what the traditional media economy bilateral market realizes is a unilateral platform economy.

As shown in Table 1, from the perspective of the resources of traditional media, it is in the most basic application layer field, and with the development of digital technology and Internet technology, there are more and more information content providers in this application layer. Therefore, in the Internet interactive information platform model, traditional media is not the only supporting platform to constitute the main body. Due to its negative crossover network externalities, the closed platform effect is becoming more and more difficult to meet the swelling information demand, and the monopoly of content products featuring news information and entertainment will be shaken. It can be seen that the traditional media economy is only the basic part of the platform economy in the future, and it is a level in the development of platformization of the media economy, and it is difficult to become the core part of the platform.

Table1. Comparison of platform expansion advantages between traditional media and new media

\begin{tabular}{|c|c|c|}
\hline $\begin{array}{c}\text { Network } \\
\text { externalities }\end{array}$ & $\begin{array}{c}\text { Traditional media } \\
\text { crossover } \\
\text { network } \\
\text { externalities }\end{array}$ & $\begin{array}{c}\text { Positive cross } \\
\text { network } \\
\text { externalities }\end{array}$ \\
\hline $\begin{array}{c}\text { Feedback } \\
\text { mechanism }\end{array}$ & $\begin{array}{c}\text { Negative } \\
\text { feedback }\end{array}$ & $\begin{array}{c}\text { Positive } \\
\text { feedback }\end{array}$ \\
\hline $\begin{array}{c}\text { Resource } \\
\text { position }\end{array}$ & $\begin{array}{c}\text { Foundation } \\
\text { position }\end{array}$ & Core position \\
\hline $\begin{array}{c}\text { Platform } \\
\text { functions }\end{array}$ & Support platform & $\begin{array}{c}\text { Interactive } \\
\text { platform }\end{array}$ \\
\hline Platform scale & Limited & Infinite \\
\hline
\end{tabular}

However, the new media will form the core part of the platform with the help of the Internet interactive information platform model. In addition, the new media and the user platform at the core of the entire platform structure generate a special network interaction state, occupying the commanding heights of the platform's core. This is because the positive feedback mechanism of the Internet has played a key role in it.

Therefore, in the development of the whole media economy platform, the position of traditional media in it has been marginalized and become the vassals of platform enterprises restricted by other core positions.

\subsection{The Profit Model of Traditional Media is Single}

The bilateral market of traditional media economy is essentially a unilateral platform economy. At the same time, due to the lack of an endogenous relationship between the advertising market and the media product market, the bilateral market of the traditional media economy can be understood as a dual unilateral market with media as the supplier: one is an advertising market with media as the supplier and advertisers as the demander the other is a media product market with media as the supply side and audience as the demand side.

(1) The profit model of the advertising market

The media sells advertising space and time to advertisers, and advertisers pay corresponding advertising fees to the media, which constitutes the basic profit model of the advertising market. The realization of this profit model strictly follows the analytical framework of traditional economics. The realization of the profit model of the advertising market depends on the media selling the media audience's time to advertisers. The lower the price the media charges its audience, the higher the price it can charge advertisers.

(2) The profit model of the media product market

The media sells media products such as information and entertainment to the audience, and the audience pays the corresponding consumption expenses to the media, which constitutes the basic profit model of the media product market.

According to the basic profit model of the advertising market, the lower the price the media charges the audience, the higher the price it can charge advertisers, so the media chooses to charge the audience a very low fee, even free, and the audience will also choose to consume at a certain price level. Therefore, this price level can be understood as a price tool for realizing platform economy in the bilateral market, that is, membership fees or registration fees charged to users.

In order to realize the basic profit model of the advertising market and the basic profit model of the media product market, a cross-network externality relationship has been formed between advertisers and audiences. There is also a negative cross-network externality between advertisers and audiences, so the media has to abandon the benefits brought by the media product market while ensuring the basic profit model of the advertising market. Therefore, the realization of the unilateral economy in the bilateral market of the traditional media economy enables itself to have a complete bilateral market profit model. This has brought potential market risks to the traditional economy, which is reflected in the following two points:

a) Firstly, a single profit model brings a single profit point. The entry of new media will greatly enhance the 
competition in the entire media market and dilute the share of the entire advertising market. Traditional media rely on a single advertising profit model and cannot adapt to such drastic changes in the market, leading to high risks in market competition.

b) Secondly, the single advertising profit model that traditional media relies on is also subject to huge pressure from the audience. Due to the lack of an endogenous relationship between advertisers and audiences, audiences are prone to platform transfers. Once the scale economy effect of the audience is lost, there will be a huge impact on the single profit point of advertising, which directly threatens the survival of the traditional media economy.

\section{New Media Platform Operation Mode under Bilateral Market Economy}

The infinite scalability of the new media platform makes it adapt to the long-tail economic theory model and meet the different needs of individualized and diversified users, which is the manifestation of the value of the development of new media platforms. The unlimited extension of the new media operating platform lies in the construction of a bilateral economic model that conforms to market logic and has reasonable standards. Such kind of bilateral economic model is no longer confined to the scope of traditional theories, and it may develop into a multilateral economic model.

\subsection{Free Mechanism}

In the platform economics, the main criterion to distinguish whether the platform market is unilateral or bilateral is the price setting policy. The pricing strategy of bilateral market is not limited to traditional pricing strategies such as cost pricing and penetration pricing. The role of price structure is not only to attract bilateral users, but also to balance bilateral users. The pricing strategy led by demand side is non intermediary, and makes the value of targeted information production higher.

In the development of new media platform, in order to make this kind of non-intermediary effect play a role, the introduction of free mechanism is the best booster. This free mechanism does not mean that there is no cost or reverse cost, but cleverly transfers the cost to other links, or through the cost allocation, makes the initial cost infinitely close to zero. Low cost is the biggest driving force of demand. The competition in the new media era has changed from the control of the production cost of information products to the continuous transfer and allocation of production costs. Delivery is the key to the bilateral economic model and the mystery of the free mechanism. Free mechanism is based on the positive feedback mechanism formed by positive network externality, which maximizes the network effect of the platform in the process of platform development.

\subsection{Attention Economy}

Scarcity and efficiency are the key concepts in economics. How to choose and distribute the scarce resources reasonably is a problem that must be faced. In the Internet age of information explosion, compared with the past human society, the biggest change of information resources endowment is the unlimited information resources. Value transfer makes every rich resource form a new kind of scarce resource. Due to the blowout of information products, the audience's attention to a certain information has become a scarce resource. In the process of competing for the market, the media platform is mainly a fight for the audience's attention. Audience's attention is limited, and with the blowout production and dissemination of information products, consumers' attention cannot last, and gradually fragmentation has become a common normal. How to gather consumers' attention has become a unique business issue in the information age. From an economic point of view, attention has become a valuable scarce resource, so whoever can attract the attention of consumers will occupy the market.

In the new media era, the development of mobile Internet technology and multi-terminal and multi-screen has changed people's way of information reading quietly. From in-depth reading of information products to fast browsing, we are using various terminals to get fragmented information, but it is difficult to be impatient for in-depth reading for us. The characteristics of Internet information resource endowments make great changes in media value: from content scarcity to attention scarcity. Microblog is a typical case. As a new media network form, its content space is always limited to 140 words. Short and concise content can attract the audience's attention when they browse all kinds of information. Users produce their own content and gather the attention of other users, which makes the development of microblog faster than that of other traditional media. It also further confirms that the development of new media platform is a more efficient and valuable business model.

Therefore, the fight for scarce attention resources is the essence of the price structure of the bilateral economic business model and the foundation of the success of the new media platform.

\subsection{Supply-Side Economies of Scope}

Under the free mechanism, how can platform companies bear market risks and ultimately make profits? From an economic point of view, this article believes that the key lies in activating the economies of scale on the demand side of the platform while expanding the economies of scope on the supply side, and promoting the transformation and realization of the former to the latter.

For information products, its price mainly depends on the marginal utility it brings to consumers. That is to say, the higher the consumer's satisfaction in consuming this information, the higher the price and the greater the value of this information product. Similarly, under the effect of the network, the larger the network scale, the greater the marginal utility of consumers, and vice versa. Therefore, the size of the network directly affects the price of information products. 
In traditional economics, price determines supply, the higher the price, the greater the output. But the information product is opposite, which is decided by the supply price. The characteristics of high fixed cost and low marginal cost of information products will make the marginal cost decrease infinitely or even close to zero when the supply is increasing. And its high fixed costs will be gradually reduced as the supply increases, and thus the price will be lower and lower. The supply curve of supply side economies of scope are shown in Figure 2.

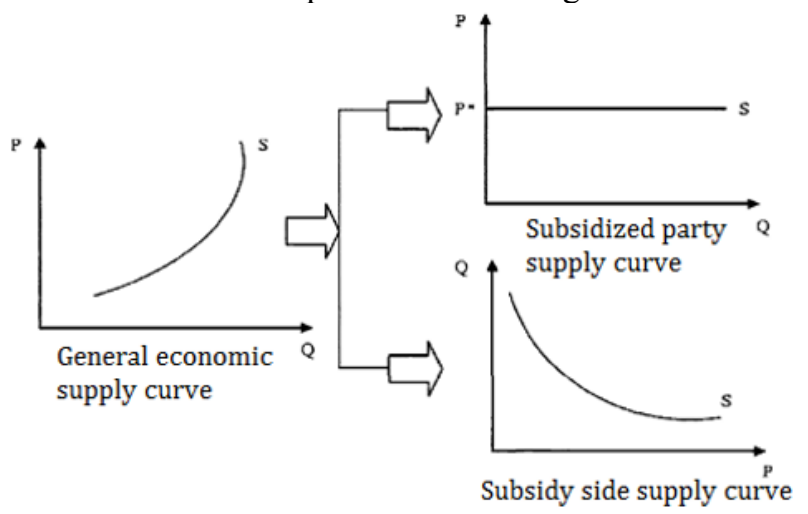

Fig2. Supply curve of supply side economies of scope

Under the influence of cross-network externalities, there are subsidizing parties and subsidized parties in the bilateral market, and their supply curves are different. For the subsidized party, the price $P$ is basically not affected by the supply $Q$. Since its cost input is fixed, there is an equilibrium price $P^{*}$, and the supply conditions can only be established if the price is maintained below $P^{*}$. When $\mathrm{P}^{*}$ tends to zero, it means the formation of a free mechanism. For the subsidy side, the more the supply Q, the lower the marginal cost, because the subsidized side makes the demand side's scale effect play a role.

We can take the realization of economies of scale on the demand side of new media platforms as the development process of potential user markets. In the actual bilateral market, there are many users and markets, which have different roles and functions for the development of new media platforms. To maximize the network effects of the new media platform, it is necessary to integrate these markets and users as much as possible, so that the direct, indirect, and cross-network effects between these users and the market have room to play. The continuous accumulation of users on the basic platform is the premise and foundation for other network effects to function. The gradual strengthening of the direct network effect on the basic platform will produce positive feedback to the economy. The accumulation of this positive feedback is the basis and foreshadowing of the winnertake-all phenomenon. As the number of platform users begins to grow geometrically, direct effects will be transformed into other network effects. At this time, the critical capacity of the number of users will drive the qualitative changes of the platform. To increase the number of users to a critical capacity in a short period of time, the free mechanism is currently the most effective means.

\section{Conclusion}

The advent of the Internet era has greatly expanded information production and information consumption. The strong development momentum of the new media industry and the increasingly mature development model have created huge economic benefits. As an industry, new media's development model and business model are not only affected by the macroeconomic environment, but also have its inherent economic logic. The development of new media platforms is the result of the development of this era. The market accumulation of the new media platform was completed in just a few decades, which greatly impacted the audiences of traditional media. Its unique network effect also gave the platform unlimited scalability and great imagination.

In this paper, we believe that the continuous driving force for the development of new media platforms is to break through the traditional single information flow profit method, and to explore the business model of valueadded service platform and the business model of integrating information flow, capital flow and logistics.

There is no doubt that the new media in the future Internet era is no longer a battle between sites, but a battle between platforms. The advantage of platform competition lies in openness, which is a necessary condition for the unlimited extension of the platform, and the standard dispute after the opening will be an absolute necessary condition for determining the competitive advantage of the platform. Whoever has the ultimate right to formulate platform standards can integrate and control new media platforms. If the third-party developers in the future will be willingly publish applications on a certain platform, then this platform is the overlord, we call it unlimited extension, unlimited integration, and realize the media economy of all platforms.

\section{References}

1. Li N, Yang Z. Bilateral Market Theory and Cultural Market Regulation:A Case Study of Television Media Control[J]. Journal of Shandong University(Philosophy and Social ences), 2016, 2(001): 264-296.

2. Xia L, Yunlong W, University S N. Literature Review of Bilateral Market and Platform Theory[J]. Academic Forum of Nandu, 2018, 5(003): 337-385.

3. Chen, N.-T.N, Dong,etc. Building a new media platform for local storytelling and civic engagement in ethnically diverse neighborhoods[J]. New Media \& Society, 2012, 22(001): 56-117.

4. Deming Z, Lin L, Liangtie T, et al. Library Service: New Media \& New Platform[J]. library journal, 2016, 12: 46-87.

5. Li Z, Ya-Qiong H U, Jun N, et al. Construction of Hospital Informatization Service Platform in the New Media Age[J]. Journal of Medical Informatics, 2015, 8(005): 122-176.

6. Yin ZC, Wang L. Communication Skills of New Media Platform for Public Welfare Publishing 
Houses[J]. Publishing Science, 2019, 027(002):81-85.

7. Zhu XN. The Application of the New Media in the Vocational Guidance of WeChat Public Platform[J]. Education and Teaching Forum, 2017, 000(036):277278.

8. Dolan T C. Social media, ACHE and me. New media platform can benefit healthcare organizations in many ways.[J]. Healthcare Executive, 2010, 25(3):6.

9. Suh B M, Park W. The Influence of Diffusion of New Media Platform in Production and Distribution of Contents Industry[J]. Journal of the Korea Industrial Information Systems Research, 2009, 002(5): 157202.

10. Jing-Jing W. Exploration and Reflection on the Innovation of College Students' Evaluation of Teaching Based on New Media Platform[J]. Education Teaching Forum, 2019, 3(006): 94-123.

11. Yang Y U, Ying X U, University S A. Moral Restraint and Legal Regulation of College Students' Speech under the New Media Platform: A Survey Based on College Students' Online Speech of a University in Shandong Province[J]. Journal of Shandong Youth University of Political Science, 2018, 4(008): 15-62.

12. Qiao L, Liang J, Xu JR, et al. The Application of Multimedia Expert System against Landscape Plant Diseases and Pests in New-media Platform A Case Study of Wechat Media Platform[J]. Sichuan Forestry Science and Technology, 2018, 039(004):87-91.

13. Liu HB. On Construction of New Media Platform in Class management in Colleges[J]. Journal of Urumqi Vocational University, 2018, 027(002):65-67.

14. Zhang N. A Study on the Construction of Higher Vocational Campus Culture in the New Media Platform[J]. Journal of Liaoning Vocational College, 2018, 020(004):93-94,106.

15. Lin LL. On the Construction and Application of Activity Platform of Radio and TV University Students from the Perspective of New Media Technology[J]. Contemporary continuing education, 2019, 037(002):69-74. 